\title{
Failure to Select Signal
}

National Cancer Institute

\section{Source}

National Cancer Institute. Failure to Select Signal. NCI Thesaurus. Code C63161.

Problem associated with the failure of the device to select the appropriate input signal. 